\title{
Attitudes, practices and information needs regarding novel influenza $A$ (H7N9) among employees of food production and operation in Guangzhou, Southern China: a cross-sectional study
}

Tiegang $\mathrm{Li}^{1+}$, Jing Feng ${ }^{1 \dagger}$, Pengzhe Qing ${ }^{1 \dagger}$, Xiaomei Fan², Weisi Liu' ${ }^{1}$, MeiXia Li and Ming Wang ${ }^{1 *}$

\begin{abstract}
Background: As of 30 May 2013, 132 human infections with avian influenza A (H7N9) had been reported in 10 Chinese cities. On 17 May 2013, because a chicken infection with H7 subtype avian influenza virus was detected in Guanzhou, Guangzhou became the 11th city to conduct emergency response operations. The goal of this study was to identify attitudes, practices and information needs among employees of food production and operation in Guangzhou.

Methods: A cross-sectional survey of face-to-face interviews was used during 17-24 June 2013. All adults seeking health examination in Guangzhou Center for Disease Control and Prevention who had lived in Guangzhou for at least 3 months, were engaged in food production and operation, and agreed to participate were interviewed.

Results: Of 1,450 participants, 69.72\% worried about being infected with the A/H7N9 and 74.41\% stated that they had searched for information about A/H7N9. The internet (76.92\%), television (67.56\%), and newspapers (56.26\%) were the main methods of obtaining information; the use of these methods differed significantly by various demographic variables $(P<0.05)$. More than one-fifth of participants complained that the information was not timely enough (20.28\%) and was intentionally concealed by the government (20.76\%). Nearly one-third (32.35\%) did not believe that the government could control the A/H7N9 epidemic. Most participants (80.76\%) reported washing hands more frequently than before, while over one-third (37.17\%) stated no longer buying poultry. A total of $84.00 \%$ indicated a willingness to receive an A/H7N9 vaccine, and the primary reason for not being willing was concern about safety (58.19\%). A history of influenza vaccination and worry about being infected with the A/H7N9 were significantly associated with intention to receive an $A / H 7 N 9$ vaccine $(P<0.05)$.

Conclusions: Our findings provide insight into the attitudes and practices of employees of food production and operation 3 months after the first human A/H7N9 case reported in China, and 1 month after infected chickens were identified in Guangzhou. Distrust in the health department should be addressed, and more effort should be made to improve compliance of proper preventive measures to reduce panic among the public. The information needs should be taken into account in the next step of health education.
\end{abstract}

Keywords: Attitudes, Health education, Influenza A (H7N9), Information needs, Practices

\footnotetext{
* Correspondence: Mingwang@gzcdc.org.cn

${ }^{+}$Equal contributors

'Guangzhou Center for Disease Control and Prevention, No 1, Qide Rd, Jiahe,

Baiyun District, Guangzhou, Guangdong Province 510440, China

Full list of author information is available at the end of the article
} 


\section{Background}

In early 2013, a novel strain of avian influenza A (H7N9) virus was detected in humans in Shanghai, Eastern China. The virus had never been reported in humans, and the World Health Organization is taking this novel A/H7N9 seriously. Most H7N9 patients have presented with respiratory tract infection with progression to severe pneumonia and breathing difficulties [1]. As of 30 May, a total of 132 human infections had been reported in 10 Chinese cities [2], of whom 37 died [3]. This yields a case fatality rate of $23.36 \%$, which is substantially higher than seasonal influenza viruses, pandemic $2009 \mathrm{~A} / \mathrm{H} 1 \mathrm{~N} 1$ virus [2], and other subgroups of $\mathrm{H} 7$ influenza A viruses (subtypes H7N2, H7N3, and H7N7) [4] in China. Although no person-toperson transmission or epidemiologic link between any of the cases has been identified, infection seemed to have involved contact with infected poultry [5]. The viral isolates from some patients were very similar to those from epidemiologically linked market chickens [5]. Furthermore, detection of more than 100 cases in 3 months compared with roughly 600 human cases of avian influenza A/H5N1 infections in a decade suggests that H7N9 is already more transmissible from poultry to humans than H5N1 [6].

As the largest trading city of southern China, Guangzhou had a large burden of both Severe Acute Respiratory Syndromes(SARS) in 2003 and pandemic influenza A (H1N1) (pH1N1) in 2009 [7]. Although no human infections with the avian influenza A (H7N9) were reported in Guangzhou, human cases have been identified in Jiangxi, Hunan, and Fujian. These three provinces all border Guangzhou, and have frequent population movement and agricultural trade with Guangzhou (Figure 1). On 17 May 2013, the Guangzhou agriculture department announced that chicken samples from a poultry market tested positive for H7 subtype avian influenza virus. This led to Guangzhou being the 11th city in China to conduct emergency response operations related to novel influenza A (H7N9).

Public cooperation in complying with infection control measures is required to minimize the spread of infectious diseases. Previous studies have demonstrated the positive correlation between a willingness to adhere to the recommendations around infection control practices and perceived infectiousness and severity of the disease [8-10], perceptions about the effectiveness of control measures [11], and trust in the information being provided by national and international public health authorities [12]. Therefore, learning more about the concerns, attitudes, and behaviors of the public during an infectious disease epidemic is crucial to improve communication efforts by public health officials [13]. Because a considerable number of H7N9 patients engaged in food-related work before symptom onset (including chef, food transporter, poultry seller and slaughter), we conducted face-to-face interviews on attitudes, practices and information needs among employees of food production and operation in Guangzhou, with an effort to assess the preparedness and response of the public, and to facilitate the development of effective prevention strategies against H7N9 infection.

\section{Methods}

Study area

Guangzhou is 7,434 square kilometers in size, situated at $22^{\circ} 26^{\prime} \mathrm{N}-23^{\circ} 56^{\prime} \mathrm{N}$ and $112^{\circ} 57^{\prime} \mathrm{E}-114^{\circ} 3^{\prime} \mathrm{E}$. As of the 2010 census, the city had over 7.9 million registered inhabitants and a floating population (such as migrant workers) of 4.8 million. It is the largest trading city in southern China, and is about $120 \mathrm{~km}$ north-northwest of Hong Kong and north-northeast of Macau (Figure 1).

\section{Participants and data collection}

In China, according to the Public Places Health Management Regulations and Implementing Rules promulgated by the Chinese government, employees of food production and operation must accept a health examination every year, and it is illegal to engage in food-related work without a valid health certificate. There are 13 health examination centers available to the public in Guangzhou, and the centrally-located Guangzhou Center for Disease Control and Prevention (CDC) Health examination center is the largest. It is typically the first choice for employees, because people with a health certificate from Guangzhou $\mathrm{CDC}$ can legally work in all 12 districts of the city.

In this study, subjects were recruited by convenience sampling from the Guangzhou CDC health examination hall. All adults seeking health examination between 1724 June 2013, who had lived in Guangzhou for at least 3 months, engaged in food production and operation, and agreed to participate in the investigation were interviewed face-to-face to complete a three-page questionnaire. Interviewers consisted of epidemiologists and dialect interpreters, and spent an average of 3 hours at a randomly chosen time of day to recruit participants. Each interview lasted about 20 minutes. All interviewers attended a 3hour pre-training before conducting interviews. Because some questions in this study were about the government's work, the responses might be untruthful if participants knew that this investigation was conducted by Guangzhou $\mathrm{CDC}$; therefore, we masked our occupation when explaining the nature of this study to interviewees.

Pilot surveys were conducted prior to the study, to confirm that participants could understand the survey questions and to ensure the validity of the questionnaire content. Using the results of this pilot study, the survey questionnaire was amended to create a final version (Additional file 1). All questions were either closed-ended or multiple-choice. 


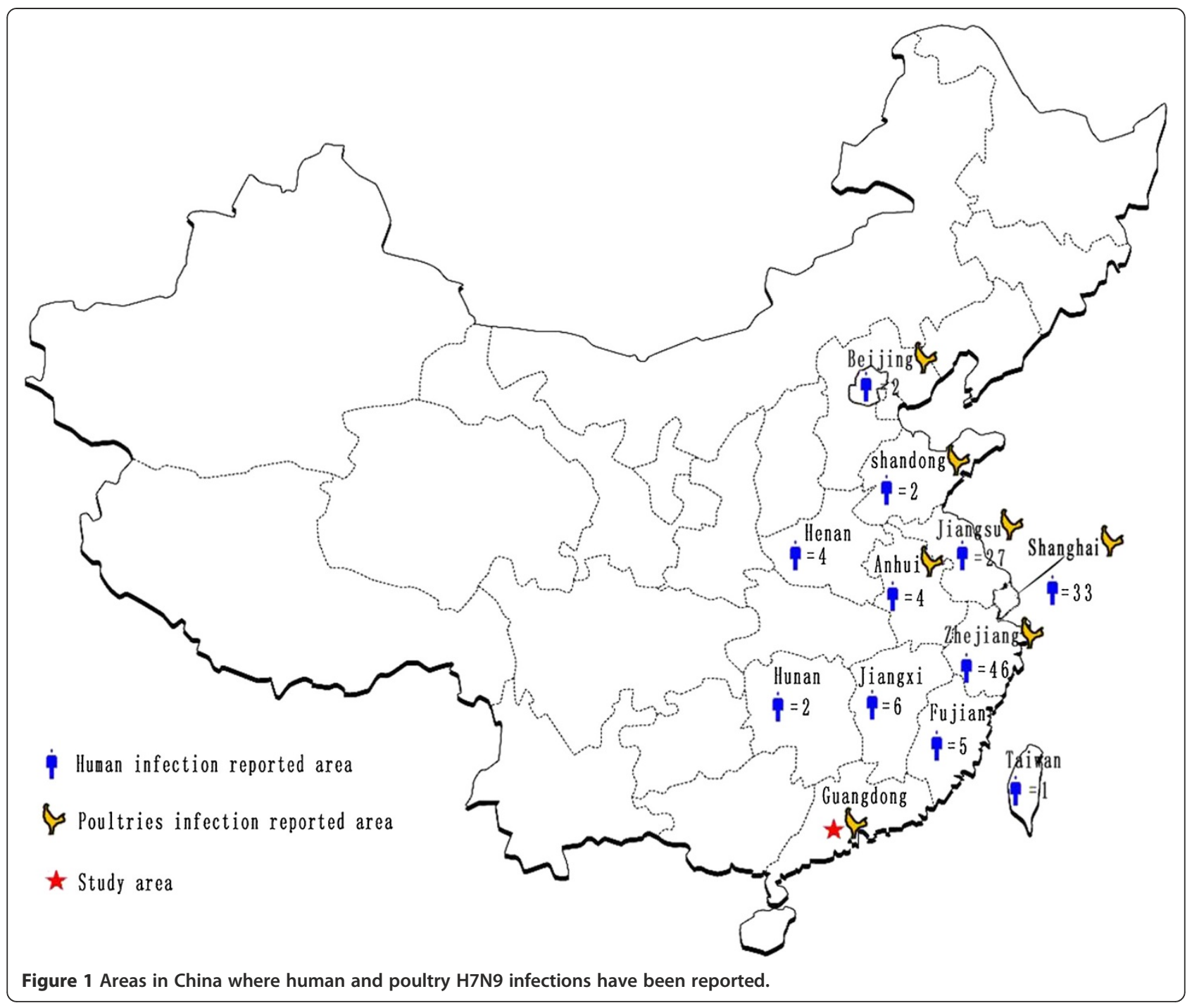

\section{Attitudes}

Nine questions were used to assess attitudes toward A/ H7N9. One item was "do you worry about getting H7N9?", and response options for this ranged from $1=$ "absolutely not" to 6 = "very worried". Six items related to "what do you think about the H7N9 information published by the government?". Each of these six items was phrased as a statement, with response options "agree" and "disagree". One item was related to "satisfaction evaluation on measures taken by the government", and response options for this ranged from 1 ="very dissatisfied" to 5 ="very satisfied". One item was "do you believe that government can control the H7N9 epidemic?", and response options for this were "yes", "hard to say", and "no".

\section{Practices}

Participants were asked 10 questions about their recent practices. One question was "did you recently search for information about H7N9?" with response options of "yes" and "no". If the response was "yes", a supplementary question of "what methods or ways did you use?" was asked. Each method/way was phrased as a statement, and response options were "yes" and "no". Seven items related to "preventive measures that have been taken after the emergence of H7N9"; all were phrased as "over the past months, I have ... because of H7N9", and the response options were "yes" and "no". Two items related to vaccines. Participants were asked "have you received an influenza vaccine in the past three years?", with response options of "yes" and "no". Participants were also asked "if the H7N9 vaccine is available, would you like to receive it". If the response was "no", we asked "why?" as the supplementary question; there were three response options to this supplementary question.

\section{Information needs}

Participants were asked to report any information needs or concerns if large numbers of human infections with 
H7N9 cases emerge or a H7N9 pandemic occurs in Guangzhou. There were 12 items for participants to respond with "yes" or "no": Four related to the epidemic situation, one related to vaccination, three related to preventive measures, three related to drug treatment, and one related to poultry safety.

\section{Demographic variables}

Demographic variables consisted of sex, age, household income, educational level, marital status, birthplace, living area, and length of time live in Guangzhou.

\section{Data analysis}

Epi Info $^{\text {тм }}$ 7.1.0.6, a free statistical software package produced by the U.S. Centers for Disease Control and Prevention, was used for data entry, cleaning, and initial analysis. Descriptive statistics, such as percentages, means, and 95\% confidence intervals, were calculated. A X2 test and/or Fisher's exact test were used to compare proportions of different groups. Multivariate logistic regression analyses were used to clarify the relationship between different methods of obtaining H7N9 information and demographic variables, and to identify the significant independent predictors of acceptance of a H7N9 vaccine, by calculating odds ratios (OR) after controlling for gender, age, and other demographics. These regression analyses were conducted using SPSS version 17.0 (SPSS Inc. 2008). $\mathrm{P}<0.05$ was considered statistically significant for all analyses.

\section{Ethical considerations}

This study was approved by the Guangzhou Center for Disease Control and Prevention.

\section{Results}

\section{Participant demographics}

Of 1,542 subjects approached, 1,450 participants accepted and successfully completed the interview, yielding a response rate of $94.03 \%$. The age ranged from 18 to 60 years old (mean: 23.91 years) (Table 1). The proportions of participants under age 25, 25-40, and over age 40 were $74.21 \%, 21.52 \%$, and $4.28 \%$, respectively. There were more females $(\mathrm{N}=986,68.00 \%)$ than males $(\mathrm{N}=464,32.00 \%)$. The majority of participants (60.90\%) lived downtown, and more than half (56.07\%) have lived in Guangzhou for more than 3 years. Nearly all (99.17\%) participants had a middle school diploma or higher. Half of the participants had an annual household income per capita less than $\$ 6,000$ (Table 1).

\section{Attitudes}

At the time of this study, which took place 3 months after the first A/H7N9 human infection was reported and 1 month after the government announced that a chicken in Guangzhou market was infected, the majority of participants (69.72\%) worried about being infected with the A/H7N9 (Table 2). When participants were asked about their opinions on H7N9 information published by the government, 73.03\% reported "accurate and transparent". However, more than a fifth (20.28\%) reported "not timely enough", and $20.76 \%$ thought "some information was intentionally concealed by the government". With regard to satisfaction on the measures taken by the government, $93.17 \%$ of participants chose "satisfied", "more satisfied", or "very satisfied". A total of $64.48 \%$ of participants believed that the government could control the H7N9 epidemic. However, nearly one-third (32.35\%) stated "hard to say" or "no" (Table 2).

\section{Practices}

After the emergence of H7N9, 74.41\% of participants stated that they had searched for information about H7N9 (Tables 3, 4). This differed by sex, with $79.09 \%$ of males and $72.21 \%$ of females $(\mathrm{P}<0.05)$ reporting searching for information. The most common method of obtaining information was "use internet" (76.92\%), followed by "watch TV" (67.56\%), and "read newspaper" (56.26\%). Males, younger participants, and those with a higher education level were more likely to choose "use internet" $(\mathrm{P}<0.05)$. However, females and older are more likely to choose "watch TV" and "read newspaper" $(\mathrm{P}<0.05)$. Compared with the middle- or high-income groups, the low-income group had a significantly higher $(\mathrm{P}<0.05)$ proportion of "watch $T V$ " (70.31\% vs. 64.72\%).

Approximately one-fifth (21.04\%) of participants chose "ask friends". This differed between sex, with $25.06 \%$ of males, and $18.68 \%$ of females reporting "inquire friends $(\mathrm{P}<0.05)$. In addition, the proportion of "ask friends" between those under 25 years old, 25-40 years old, and over 40 years old was $22.48 \%, 19.03 \%$, and $8.16 \%$, respectively. This trend reached statistical significance (Trend $\chi^{2}=6.46$, $\mathrm{P}=0.04)$.

A total of $13.72 \%$ of participants reported "listen to the radio" to get H7N9 information. This differed among age groups, with $11.24 \%$ of those under 25 years, $20.24 \%$ of those aged $25-40$ years, and $20.41 \%$ of those over 40 years old reporting "listen to the radio" (Trend $\chi^{2}=$ $14.80, \mathrm{P}=0.00)$. Moreover, $12.79 \%$ of participants chose "consult doctor", which was significantly higher in males than in females (16.08\% vs. $11.10 \%)$.

Regarding the preventive measures, $80.76 \%$ of participants reported washing hands more often than usual, which was significantly higher $(\mathrm{P}<0.05)$ in females $(82.25 \%)$ than in males $(77.59 \%)$. In addition, a total of $68.27 \%$ reported ventilating rooms (by opening windows and doors) more frequently than before. Roughly half of the participants $(48.76 \%)$ cancelled or postponed their social events, and this was significantly higher in females than in males $(52.13 \%$ vs. $41.95 \%)$. Of particular note, over 
Table 1 Demographic characteristics of study participants in Guangzhou, 17-24 June 2013 (N = 1,450)

\begin{tabular}{|c|c|c|c|c|}
\hline Characteristics & No. & $\%$ & 95\% Cl Lower & 95\% Cl Upper \\
\hline \multicolumn{5}{|l|}{ Age group(years) } \\
\hline$<25$ & 1076 & 74.21 & 71.86 & 76.43 \\
\hline $25-40$ & 312 & 21.52 & 19.45 & 23.74 \\
\hline$>40$ & 62 & 4.28 & 3.32 & 5.48 \\
\hline \multicolumn{5}{|l|}{ sex } \\
\hline Male & 464 & 32.00 & 29.62 & 34.48 \\
\hline Female & 986 & 68.00 & 65.52 & 70.38 \\
\hline \multicolumn{5}{|l|}{ Annual household income per capita } \\
\hline Less than $\$ 2,000$ & 151 & 10.41 & 8.91 & 12.13 \\
\hline$\$ 2,001-\$ 6,000$ & 577 & 39.79 & 37.27 & 42.37 \\
\hline$\$ 6,001-\$ 10,000$ & 476 & 32.83 & 30.42 & 35.32 \\
\hline$\$ 10,001-\$ 20,000$ & 180 & 12.41 & 10.78 & 14.25 \\
\hline$>\$ 20,000$ & 66 & 4.55 & 3.56 & 5.79 \\
\hline \multicolumn{5}{|l|}{ Residence time in Guangzhou } \\
\hline Less than 1 year & 348 & 24.00 & 21.84 & 26.30 \\
\hline $1-3$ years & 279 & 19.24 & 17.26 & 21.39 \\
\hline$\geq 3$ years & 813 & 56.07 & 53.47 & 58.64 \\
\hline Refused & 10 & 0.69 & 0.35 & 1.31 \\
\hline \multicolumn{5}{|l|}{ Highest education } \\
\hline Non-educated & 5 & 0.34 & 0.13 & 0.85 \\
\hline Primary school graduate & 7 & 0.48 & 0.21 & 1.04 \\
\hline Middle school graduate & 189 & 13.03 & 11.37 & 14.90 \\
\hline High school graduate & 560 & 38.62 & 36.11 & 41.19 \\
\hline College: $1-3$ years technical school training & 283 & 19.52 & 17.53 & 21.67 \\
\hline College: 4 years or more (college graduate) & 400 & 27.59 & 25.31 & 29.98 \\
\hline Master or doctor degree graduate & 6 & 0.41 & 0.17 & 0.95 \\
\hline \multicolumn{5}{|l|}{ Living area } \\
\hline Suburban or rural & 558 & 38.48 & 35.98 & 41.05 \\
\hline Downtown & 883 & 60.90 & 58.32 & 63.41 \\
\hline Refused & 9 & 0.62 & 0.30 & 1.22 \\
\hline
\end{tabular}

$\mathrm{Cl}=$ Confidence Intervals.

one-third (37.17\%) of participants reported no longer buying chickens, ducks, geese and other poultry, and this was higher in females than in males $(40.97 \%$ vs. $29.09 \%)$ (Tables 3, 4).

Regarding vaccination, $84.00 \%$ of participants reported that they would accept an A/H7N9 influenza vaccine if it is available. The primary reason for not accepting the new vaccine was "worry about safety" (58.19\%), followed by "not necessary, I would not be infected with H7N9" (24.57\%), and "do not want spend money to immunize, if it is free, I will" (14.22\%) (Figure 2).

\section{Information needs}

When participants were asked about their information needs if there were an outbreak of H7N9 in Guangzhou, the highest proportion of responses was "how to protect my family from infection?" (75.31\%), followed by "what is the current epidemic situation?"(71.86\%), "is the vaccination available? Is it safe?" (63.10\%), "is there any effective drug treatment?" (62.55\%), and "how to conduct home disinfection?" (50.41\%) (Table 5).

\section{Multivariate analysis}

Because different methods of obtaining H7N9 information varied significantly with some of demographic variables (indicated by the chi-square test on univariate analysis; Tables 3,4), we conducted multivariate analyses to determine which independent variables are significant in logistic regression models, with non-significant variables also entered into the models. The results are shown in Tables 6, 7 . 
Table 2 Attitudes towards A(H7N9) influenza among employees of food production and operation in Guangzhou, 17-24 June 2013

\begin{tabular}{|c|c|c|c|c|}
\hline Items & No. & $\%$ & 95\% Cl lower & $95 \% \mathrm{Cl}$ upper \\
\hline \multicolumn{5}{|l|}{ Did you worry about getting H7N9 virus? } \\
\hline Very worry & 254 & 17.52 & 15.61 & 19.59 \\
\hline More worry & 296 & 20.41 & 18.39 & 22.60 \\
\hline Worry & 461 & 31.79 & 29.41 & 34.27 \\
\hline Not to matter & 48 & 3.31 & 2.48 & 4.40 \\
\hline Not worry & 391 & 26.97 & 24.71 & 29.34 \\
\hline Absolutely not worry & 0 & 0.00 & 0.00 & 0.00 \\
\hline \multicolumn{5}{|l|}{ How do you think about the H7N9 information published by government? } \\
\hline Accurate and transparent & 1059 & 73.03 & 70.66 & 75.29 \\
\hline Not timely enough & 294 & 20.28 & 18.25 & 22.46 \\
\hline Difficult to understand, more puzzling & 205 & 14.14 & 12.41 & 16.06 \\
\hline Publics have limited access to get correct and authority information & 235 & 16.21 & 14.37 & 18.23 \\
\hline The information was intentionally concealed by Government & 301 & 20.76 & 18.72 & 22.96 \\
\hline The severity of epidemic was deliberately exaggerated by government, causing panic & 104 & 7.17 & 5.92 & 8.65 \\
\hline \multicolumn{5}{|l|}{ How about your personal satisfaction evaluation on the measures taken by government? } \\
\hline Very dissatisfied & 94 & 6.48 & 5.30 & 7.91 \\
\hline Dissatisfied & 5 & 0.34 & 0.13 & 0.85 \\
\hline Satisfied & 248 & 17.10 & 15.22 & 19.16 \\
\hline More satisfied & 546 & 37.66 & 35.16 & 40.21 \\
\hline Very satisfied & 557 & 38.41 & 35.91 & 40.98 \\
\hline \multicolumn{5}{|l|}{ Do you believe that government can control the H7N9 epidemic? } \\
\hline Yes & 935 & 64.48 & 61.95 & 66.94 \\
\hline Hard to say & 439 & 30.28 & 27.93 & 32.73 \\
\hline No & 30 & 2.07 & 1.42 & 2.98 \\
\hline Refused & 46 & 3.17 & 2.36 & 4.24 \\
\hline
\end{tabular}

$\mathrm{Cl}=$ Confidence Intervals.

In model $\mathrm{A}$, sex did not remain significant on multivariate analysis $(\mathrm{P}>0.05)$. Younger $(\leq 40$ years) and more education were significantly associated with higher likelihood of using the internet $(\mathrm{P}<0.05)$. Model $\mathrm{B}$ indicated that females and those with a higher income had a significantly higher likelihood of watching TV $(\mathrm{P}<0.05)$, and model $\mathrm{C}$ indicated that females had a significantly higher likelihood of reading the newspaper $(\mathrm{P}<0.05)$. Model $\mathrm{D}$ indicated that being male and younger (under 25 years) was significantly with higher likelihood of inquiring friends $(\mathrm{P}<0.05)$, model $\mathrm{E}$ indicated that older participants (over 40 years) were significantly more likely to listen to the radio $(\mathrm{P}<$ 0.05 ), and model $F$ indicated that being male was significantly associated with a higher likelihood of consulting a doctor $(P<0.05)$. In addition, because sex and age were both significant in model $\mathrm{D}$, we further conducted an interaction analysis. The interaction term (sex*age) was found to not be significant $(P>0.05)$, so we excluded it from the final model.
We also conducted multivariate analysis of willingness to accept H7N9 vaccine, with possible predictor variables and demographics (including sex, age group, marital status, education level, living area, annual income, and place of birth) included in the logistic regression model. Influenza vaccination within the past 3 years $(\mathrm{OR}=1.97, \mathrm{P}<$ $0.05)$ and worry about being infected with the A/H7N9 (compared to "not worried", OR for "worried" $=2.06$, OR for "more worried" $=2.78$, and OR for "very worried" = 3.58; $\mathrm{P}<0.05$ for all three) were significantly associated with willingness to receive an H7N9 vaccine (Table 8).

\section{Discussion}

To our knowledge, this is the first study that focuses on understanding the public's awareness of and attitudes toward influenza A (H7N9). In a previous study designed to assess the implications of public understanding of avian influenza, researchers found that the majority of participants did not believe a pandemic would occur, and believed 
Table 3 Precautionary practices against A(H7N9) influenza in Guangzhou, 17-24 June 2013

\begin{tabular}{|c|c|c|c|c|c|c|c|c|c|c|c|}
\hline \multirow[t]{2}{*}{ Items } & \multicolumn{2}{|c|}{ Total } & \multicolumn{4}{|c|}{ Sex } & \multicolumn{5}{|c|}{ Age } \\
\hline & No. & $\%$ & Male & Female & $x^{2}$ & $\mathbf{P}$ & $<25$ & $25-40$ & $>40$ & Trend $x^{2}$ & $\mathbf{P}$ \\
\hline $\begin{array}{l}\text { Did you recently search some information about H7N9? } \\
\text { (response = "yes") }\end{array}$ & 1079 & 74.41 & $367(79.09 \%)$ & $712(72.21 \%)$ & 7.58 & $0.00^{*}$ & $783(72.77 \%)$ & $247(79.17)$ & 49 (79.03\%) & 5.92 & 0.06 \\
\hline \multicolumn{12}{|l|}{ If yes, what methods did you use to get information? } \\
\hline Use internet & 830 & 76.92 & $297(80.93 \%)$ & $533(74.86 \%)$ & 5.02 & $0.03^{*}$ & $633(80.84 \%)$ & $173(70.04 \%)$ & $24(48.98 \%)$ & 34.92 & $0.00^{*}$ \\
\hline Watch TV & 729 & 67.56 & 231 (62.94\%) & 498 (69.94\%) & 5.41 & $0.02^{*}$ & $511(65.26 \%)$ & $183(74.09 \%)$ & 35 (71.43\%) & 7.02 & $0.03^{*}$ \\
\hline Read newspaper & 607 & 56.26 & $179(48.77 \%)$ & $428(60.11 \%)$ & 12.66 & $0.00^{*}$ & 429 (54.79\%) & 151 (61.13\%) & 34 (69.39\%) & 6.57 & $0.01^{*}$ \\
\hline Ask friends & 227 & 21.04 & 94 (25.06\%) & $133(18.68 \%)$ & 7.01 & $0.01^{*}$ & $176(22.48 \%)$ & 47 (19.03\%) & $4(8.16 \%)$ & 6.46 & $0.04^{*}$ \\
\hline Listen to the radio & 148 & 13.72 & 49 (13.35\%) & 99 (13.90\%) & 0.06 & 0.80 & 88 (11.24\%) & $50(20.24 \%)$ & 10 (20.41\%) & 14.80 & $0.00^{*}$ \\
\hline Consult doctor & 138 & 12.79 & $59(16.08 \%)$ & 79 (11.10\%) & 5.38 & $0.02^{*}$ & $101(12.90 \%)$ & $34(13.77 \%)$ & $3(6.12 \%)$ & 2.17 & 0.33 \\
\hline $\begin{array}{l}\text { Have you injected flu vaccine in the past } 3 \text { years? } \\
\text { (response = "yes") }\end{array}$ & 481 & 33.17 & $180(38.79 \%)$ & 301 (30.53\%) & 9.72 & $0.00^{*}$ & 369 (36.80\%) & $74(23.72 \%)$ & 11 (17.74\%) & 25.64 & $0.00^{*}$ \\
\hline \multicolumn{12}{|l|}{$\begin{array}{l}\text { After emergence of } \mathrm{H} 7 \mathrm{~N} 9 \text {, what protective measures } \\
\text { have you taken? }\end{array}$} \\
\hline Washed hands more often than usual & 1171 & 80.76 & $360(77.59 \%)$ & $811(82.25 \%)$ & 4.42 & $0.04^{*}$ & $881(81.88 \%)$ & $241(77.24 \%)$ & 49 (79.03\%) & 3.47 & 0.18 \\
\hline Ventilate room more frequency & 990 & 68.27 & $312(67.24 \%)$ & $678(68.46 \%)$ & 0.33 & 0.56 & $735(68.31 \%)$ & $216(69.23 \%)$ & $39(62.90 \%)$ & 0.96 & 0.62 \\
\hline Cancelled or postponed social events & 707 & 48.76 & $193(41.95 \%)$ & $514(52.13 \%)$ & 14.01 & $0.00^{*}$ & $520(48.33 \%)$ & $161(51.60 \%)$ & $26(41.94 \%)$ & 2.46 & 0.33 \\
\hline Bought some drugs for preparation & 582 & 40.14 & $175(37.72 \%)$ & $407(41.28 \%)$ & 1.66 & $0.20^{*}$ & $434(40.33 \%)$ & $121(38.78 \%)$ & $27(43.55 \%)$ & 0.55 & 0.76 \\
\hline No longer bought poultries to eat & 539 & 37.17 & $135(29.09 \%)$ & $404(40.97 \%)$ & 19.06 & $0.00^{*}$ & $391(36.34 \%)$ & $130(41.67 \%)$ & $18(29.03 \%)$ & 4.78 & 0.09 \\
\hline Reduced the amount I go into shops & 416 & 28.69 & $131(28.23 \%)$ & $285(28.90 \%)$ & 0.07 & 0.79 & $312(29.00 \%)$ & $87(27.88 \%)$ & 17 (27.42\%) & 0.20 & 0.91 \\
\hline
\end{tabular}


Table 4 Precautionary practices against A(H7N9) influenza in Guangzhou, 17-24 June 2013

\begin{tabular}{|c|c|c|c|c|c|c|c|c|c|c|c|c|}
\hline \multirow[t]{2}{*}{ Items } & \multicolumn{4}{|c|}{ Education } & \multicolumn{5}{|c|}{ Income per capita } & \multicolumn{3}{|c|}{ Living area } \\
\hline & $\begin{array}{l}\text { Lower than } \\
\text { college graduate }\end{array}$ & $\begin{array}{l}\text { College graduate } \\
\text { and higher }\end{array}$ & $x^{2}$ & p & $\begin{array}{l}\text { Less than } \\
\$ 6,000\end{array}$ & $>\$ 6,000$ & $x^{2}$ & $\mathbf{P}$ & Suburban or rural & Downtown & $x^{2}$ & $\mathbf{P}$ \\
\hline $\begin{array}{l}\text { Did you recently search some information about } \\
\text { H7N9? (response = "yes") }\end{array}$ & $581(76.35 \%)$ & $498(72.28 \%)$ & 3.14 & 0.08 & $530(72.80 \%)$ & $549(76.40 \%)$ & 1.99 & 0.16 & $411(73.66 \%)$ & $663(75.08 \%)$ & 0.37 & 0.54 \\
\hline \multicolumn{13}{|l|}{ If yes, what methods did you use to get information? } \\
\hline Use internet & $418(71.94 \%)$ & $412(82.73 \%)$ & 17.6 & $0.00^{*}$ & $414(78.11 \%)$ & $416(75.77 \%)$ & 0.83 & 0.36 & $325(79.08 \%)$ & $502(75.72 \%)$ & 1.62 & 0.20 \\
\hline Watch TV & $398(68.50 \%)$ & $331(66.47 \%)$ & 0.51 & 0.48 & $343(64.72 \%)$ & $386(70.31 \%)$ & 3.87 & $0.04^{*}$ & $282(68.61 \%)$ & $445(67.12 \%)$ & 0.26 & 0.61 \\
\hline Read newspaper & $324(55.77 \%)$ & $283(56.83 \%)$ & 0.12 & 0.73 & $308(58.11 \%)$ & $299(54.46 \%)$ & 1.46 & 0.23 & $227(55.23 \%)$ & $377(56.86 \%)$ & 0.27 & 0.60 \\
\hline Ask friends & $123(21.17 \%)$ & $104(20.88 \%)$ & 0.01 & 0.90 & $118(22.26 \%)$ & $109(19.85 \%)$ & 0.94 & 0.33 & $90(21.90 \%)$ & $136(20.51 \%)$ & 0.29 & 0.59 \\
\hline Listen to the radio & $81(13.94 \%)$ & $67(13.45 \%)$ & 0.05 & 0.81 & $68(12.83 \%)$ & $80(14.57 \%)$ & 0.69 & 0.41 & $60(14.60 \%)$ & $87(13.12 \%)$ & 0.47 & 0.49 \\
\hline Consult doctor & $84(14.46 \%)$ & $54(10.84 \%)$ & 3.14 & 0.07 & $68(12.83 \%)$ & $70(12.75 \%)$ & 0.00 & 0.97 & $59(14.36 \%)$ & $77(11.61 \%)$ & 1.72 & 0.19 \\
\hline $\begin{array}{l}\text { Have you injected flu vaccine in the past } 3 \text { years? } \\
\text { (response = "yes") }\end{array}$ & $260(34.17 \%)$ & $221(32.08 \%)$ & 0.71 & 0.40 & $231(31.73 \%)$ & $250(34.63 \%)$ & 1.37 & 0.24 & $203(36.38 \%)$ & $276(31.26 \%)$ & 4.04 & $0.04^{*}$ \\
\hline \multicolumn{13}{|l|}{$\begin{array}{l}\text { After emergence of } \mathrm{H} 7 \mathrm{~N} 9 \text {, what protective measures } \\
\text { have you taken? }\end{array}$} \\
\hline Washed hands more often than usual & $605(79.50 \%)$ & $566(82.15 \%)$ & 1.63 & 0.20 & $576(79.12 \%)$ & $595(82.41 \%)$ & 2.52 & 0.11 & $448(80.29 \%)$ & $717(81.20 \%)$ & 0.18 & 0.67 \\
\hline Ventilate room more frequency & $247(36.01 \%)$ & $265(38.46 \%)$ & 0.93 & 0.33 & 485 (66.62\%) & $505(69.94 \%)$ & 1.85 & 0.17 & $391(70.07 \%)$ & $592(67.04 \%)$ & 1.45 & 0.23 \\
\hline Cancelled or postponed social events & $353(46.39 \%)$ & $354(51.38 \%)$ & 3.60 & 0.06 & $369(50.69 \%)$ & $338(46.81 \%)$ & 2.18 & 0.14 & $271(48.57 \%)$ & $430(48.70 \%)$ & 0.00 & 0.96 \\
\hline Bought some drugs for preparation & $311(40.87 \%)$ & $271(39.33 \%)$ & 0.35 & 0.55 & $301(41.35 \%)$ & $281(38.92 \%)$ & 0.89 & 0.35 & $218(39.07 \%)$ & $359(40.66 \%)$ & 0.36 & 0.55 \\
\hline No longer bought poultries to eat & $274(36.01 \%)$ & $265(38.46 \%)$ & 0.93 & 0.33 & $253(34.75 \%)$ & $286(39.61 \%)$ & 3.66 & 0.06 & $221(39.61 \%)$ & $315(35.67 \%)$ & 2.26 & 0.13 \\
\hline Reduced the amount I go into shops & $207(27.20 \%)$ & 209 (30.33\%) & 0.17 & 0.19 & $215(29.53 \%)$ & $201(27.84 \%)$ & 0.51 & 0.48 & $162(29.03 \%)$ & $251(28.43 \%)$ & 0.06 & 0.80 \\
\hline
\end{tabular}




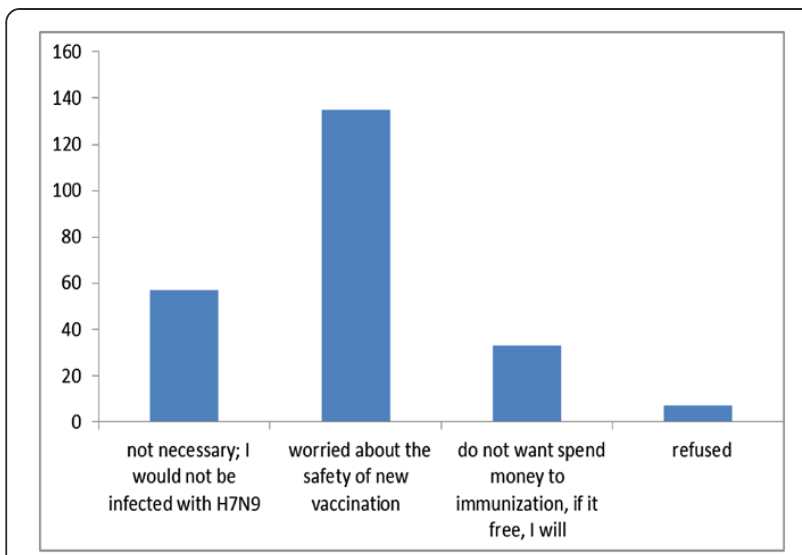

Figure 2 Reasons for participants to accept an A(H7N9) influenza vaccine in Guangzhou, 17-24 June $2013(\mathrm{~N}=232)$.

that dealing with the disease was the responsibility of the government [14]. Opinions about the credibility of health information varied from distrust to belief in the credibility of information released by the local health department [11]. Our current study demonstrated that $69.72 \%$ of participants worried about being infected with the A/H7N9. Despite the fact that the majority of participants (73.03\%) thought the H7N9 information published by the government was accurate and transparent, over one-fifth (20.28\%) complained it was not timely enough, and $20.76 \%$ thought some information was intentionally concealed by the government. Furthermore, when asked "do you believe that the government can control the H7N9 epidemic?", nearly one-third of participants (30.28\%) responded with "hard to say". These findings reflect some distrust in the announcements of the health department. This may be because the public did not accept the long interval between the time when cases were identified and the time that information was released to public, as well as the increasing number of cases and infected areas.
We found that after the emergence of H7N9, a majority of participants actively searched for information about H7N9, and the primary method of obtaining information was using the internet. This result is consistent with other studies that indicated that the internet is increasingly used by the public as the most important source of healthrelated information [15]. Furthermore, our data also indicate that different methods of obtaining information were significantly associated with different demographic variables. For example, younger and more educated participants were significantly more likely to use the internet, while female and higher-income participants were significantly more likely to watch TV. Females were also more likely to read a newspaper for information. Although few participants (13.72\%) chose "listen to the radio", older participants were more likely to get information from the radio than younger participants. This suggests that the transmission of heath information should consider the demographic characteristics of the target audience in determining which methods to emphasize. In addition, it is worth noting that among the young participants, over one-fifth chose "ask friends" rather than seeking a more formal information source. This should be addressed in targeting intervention efforts specifically at young people.

Our study demonstrated that most subjects (80.76\%) reported washing their hands more often than usual. Similar findings were also reported at the beginning of the H1N1 influenza pandemic in Hong Kong [16], and in the United Kingdom, 28\% of subjects reported changing their hand washing behavior as a result of H1N1 influenza [10]. We also found that of participants $68.27 \%$ reported ventilating rooms more frequently than before, and nearly half $(48.76 \%)$ cancelled or postponed their social events because of $\mathrm{A} / \mathrm{H} 7 \mathrm{~N} 9$. When viewed together, the data from these studies implies that preventative health behaviors become more prevalent during infectious disease epidemics. Furthermore, our data revealed

Table 5 Participants' information needs in response to "once H7N9 outbreaks in Guangzhou"

\begin{tabular}{|c|c|c|c|c|}
\hline Items & No. & $\%$ & 95\% Cl lower & $95 \% \mathrm{Cl}$ upper \\
\hline How to protect my family from infection? & 1092 & 75.31 & 72.99 & 77.49 \\
\hline What is the current epidemic situation? & 1042 & 71.86 & 69.46 & 74.15 \\
\hline Is the vaccination available? Is it safe? & 915 & 63.10 & 60.55 & 65.58 \\
\hline Is there any effective drug treatment? & 907 & 62.55 & 60.00 & 65.04 \\
\hline How to conduct home disinfection? & 731 & 50.41 & 47.81 & 53.02 \\
\hline What kind of food can increase resistance of body to the virus? & 713 & 49.17 & 46.57 & 51.78 \\
\hline Can the virus transmit from person to person? & 637 & 43.93 & 41.36 & 46.53 \\
\hline How to do if I suspect I am infected with H7N9? & 616 & 42.48 & 39.93 & 45.08 \\
\hline How to visit hospital? & 589 & 40.62 & 38.09 & 43.20 \\
\hline How can we get reliable information on the disease? & 545 & 37.59 & 35.10 & 40.14 \\
\hline What preparatory work has been done by health department? & 512 & 35.31 & 32.86 & 37.84 \\
\hline
\end{tabular}

$\mathrm{Cl}=$ Confidence Intervals. 
Table 6 Multivariate regression analysis of the impact of various factors on the methods of obtaining H7N9 information

\begin{tabular}{|c|c|c|c|c|c|c|c|c|c|}
\hline \multirow[t]{2}{*}{ Independent variables } & \multicolumn{3}{|c|}{ Model A: Use internet } & \multicolumn{3}{|c|}{ Model B: Watch TV } & \multicolumn{3}{|c|}{ Model C: Read newspaper } \\
\hline & $P$ & OR & OR $95 \% \mathrm{Cl}$ & $\mathbf{P}$ & OR & OR $95 \% \mathrm{Cl}$ & $\mathbf{P}$ & OR & OR $95 \% \mathrm{Cl}$ \\
\hline \multicolumn{10}{|l|}{ Sex } \\
\hline Female & - & 1.00 & - & - & 1.00 & - & - & 1.00 & - \\
\hline Male & 0.13 & 1.28 & $0.92-1.75$ & $0.03^{*}$ & 0.74 & $0.56-0.96$ & $0.00^{*}$ & 0.63 & $0.48-0.81$ \\
\hline \multicolumn{10}{|l|}{ Annual income } \\
\hline$\leq \$ 6,000$ & - & 1.00 & - & - & 1.00 & - & - & 1.00 & - \\
\hline$>\$ 6,000$ & 0.19 & 0.82 & $0.61-1.10$ & $0.04^{*}$ & 1.29 & $1.11-1.67$ & 0.17 & 0.84 & $0.66-1.07$ \\
\hline \multicolumn{10}{|l|}{ Education level } \\
\hline Lower than college graduate & - & 1.00 & - & - & 1.00 & - & - & 1.00 & - \\
\hline College graduate and higher & $0.00^{*}$ & 1.62 & $1.18-2.19$ & 0.80 & 0.97 & $0.74-1.25$ & 0.29 & 1.15 & $0.89-1.47$ \\
\hline \multicolumn{10}{|l|}{ Living area } \\
\hline Suburban or rural & - & 1.00 & - & - & 1.00 & - & - & 1.00 & - \\
\hline Downtown & 0.65 & 0.93 & $0.68-1.26$ & 0.47 & 0.91 & $0.69-1.18$ & 0.82 & 1.03 & $0.80-1.32$ \\
\hline \multicolumn{10}{|l|}{ Age } \\
\hline$>40$ years & - & 1.00 & - & - & 1.00 & - & - & 1.00 & - \\
\hline $25-40$ years & $0.02^{*}$ & 2.17 & $1.15-4.08$ & 0.70 & 1.15 & $0.57-2.28$ & 0.37 & 1.34 & $0.71-2.49$ \\
\hline$<25$ years & $0.00^{*}$ & 3.58 & $1.95-6.52$ & 0.43 & 0.77 & $0.40-1.47$ & 0.94 & 1.02 & $0.56-1.85$ \\
\hline Constant & $0.04^{*}$ & 1.17 & - & $0.01^{*}$ & 2.60 & - & $0.08^{*}$ & 1.40 & - \\
\hline
\end{tabular}

$\mathrm{Cl}=$ Confidence Intervals, $\mathrm{OR}=$ Odds Ratio.

${ }^{*} \mathrm{P}<0.05$.

Table 7 Multivariate regression analysis of the impact of various factors on the methods of obtaining H7N9 information

\begin{tabular}{|c|c|c|c|c|c|c|c|c|c|}
\hline \multirow[t]{2}{*}{ Independent variables } & \multicolumn{3}{|c|}{ Model D: Inquire friends } & \multicolumn{3}{|c|}{ Model E: Listen to the radio } & \multicolumn{3}{|c|}{ Model F: Consult doctor } \\
\hline & $\mathbf{P}$ & OR & OR $95 \% \mathrm{Cl}$ & $\mathbf{P}$ & OR & OR $95 \% \mathrm{Cl}$ & $\mathbf{P}$ & OR & OR $95 \% \mathrm{Cl}$ \\
\hline \multicolumn{10}{|l|}{ Sex } \\
\hline Female & - & 1.00 & - & - & 1.00 & - & - & 1.00 & - \\
\hline Male & $0.01^{*}$ & 1.47 & $1.08-1.99$ & 0.91 & 0.98 & $0.67-1.42$ & $0.02^{*}$ & 1.56 & $1.07-2.25$ \\
\hline \multicolumn{10}{|l|}{ Annual income } \\
\hline$\leq \$ 6,000$ & - & 1.00 & - & - & 1.00 & - & - & 1.00 & - \\
\hline$>\$ 6,000$ & 0.36 & 0.87 & $0.64-1.16$ & 0.47 & 1.14 & $0.80-1.62$ & 0.90 & 1.03 & $0.71-1.47$ \\
\hline \multicolumn{10}{|l|}{ Education level } \\
\hline Lower than college graduate & - & 1.00 & - & - & 1.00 & - & - & 1.00 & - \\
\hline College graduate and higher) & 0.44 & 0.89 & $0.65-1.20$ & 0.69 & 1.08 & $0.74-1.55$ & 0.09 & 0.77 & $0.66-1.04$ \\
\hline \multicolumn{10}{|l|}{ Living area } \\
\hline Suburban or rural & - & 1.00 & - & - & 1.00 & - & - & 1.00 & - \\
\hline Downtown & 0.91 & 0.98 & $0.72-1.33$ & 0.31 & 0.83 & $0.58-1.19$ & 0.22 & 0.79 & $0.55-1.14$ \\
\hline \multicolumn{10}{|l|}{ Age } \\
\hline$>40$ years & - & 1.00 & - & - & 1.00 & - & - & 1.00 & - \\
\hline $25-40$ years & 0.08 & 2.64 & $0.89-7.73$ & 0.86 & 0.93 & $0.43-2.01$ & 0.15 & 2.45 & $0.71-8.36$ \\
\hline$<25$ years & $0.03^{*}$ & 3.24 & $1.13-9.22$ & $0.04^{*}$ & 0.46 & $0.21-0.96$ & 0.17 & 2.34 & $0.70-7.75$ \\
\hline Constant & $0.00^{*}$ & 0.09 & - & $0.00^{*}$ & 0.28 & - & $0.00^{*}$ & 0.07 & - \\
\hline
\end{tabular}

$\mathrm{Cl}=$ Confidence Intervals, $\mathrm{OR}=$ Odds Ratio. 
Table 8 Multivariate regression analysis of the impact of various factors on willingness to accept H7N9 vaccine

\begin{tabular}{|c|c|c|c|c|c|}
\hline Independent variables & B & SE & $\mathbf{P}$ & OR & $95 \% \mathrm{Cl}$ for $\mathrm{OR}$ \\
\hline \multicolumn{6}{|l|}{ Sex } \\
\hline Female & - & - & - & 1.00 & - \\
\hline Male & 0.10 & 0.16 & 0.54 & 1.11 & $0.80-1.51$ \\
\hline \multicolumn{6}{|l|}{ Education level } \\
\hline Lower than college graduate & - & - & - & 1.00 & - \\
\hline College graduate and higher & -0.14 & 0.15 & 0.36 & 0.87 & $0.64-1.17$ \\
\hline \multicolumn{6}{|l|}{ Living area } \\
\hline Suburban or rural & - & - & - & 1.00 & - \\
\hline Downtown & 0.03 & 0.15 & 0.86 & 1.03 & $0.76-1.38$ \\
\hline \multicolumn{6}{|l|}{ Annual income } \\
\hline$\leq \$ 6,000$ & - & - & - & 1.00 & - \\
\hline$>\$ 6,000$ & 0.22 & 0.15 & 0.13 & 1.25 & $0.93-1.67$ \\
\hline \multicolumn{6}{|l|}{ Age } \\
\hline$>40$ years & - & - & - & 1.00 & - \\
\hline $25-40$ years & -0.10 & 0.36 & 0.79 & 0.91 & $0.44-1.84$ \\
\hline$<25$ years & 0.03 & 0.18 & 0.85 & 1.03 & $0.72-1.47$ \\
\hline \multicolumn{6}{|l|}{ Place of birth } \\
\hline Others & - & - & - & 1.00 & - \\
\hline Guangzhou & 0.04 & 0.22 & 0.73 & 1.04 & $0.96-1.71$ \\
\hline \multicolumn{6}{|l|}{ Marital status } \\
\hline Single & - & - & - & 1.00 & - \\
\hline Married/once married & 0.11 & 0.31 & 0.52 & 1.11 & $0.86-1.58$ \\
\hline \multicolumn{6}{|c|}{ Received influenza vaccine in recent 3 years } \\
\hline No & - & - & - & 1.00 & - \\
\hline Yes & 0.68 & 0.18 & $0.00^{*}$ & 1.97 & $1.38-2.78$ \\
\hline \multicolumn{6}{|l|}{ Worry about being infected with H7N9 } \\
\hline No worry & - & - & - & 1.00 & - \\
\hline Not to matter & -0.24 & 0.34 & 0.48 & 0.79 & $0.40-1.52$ \\
\hline Worry & 0.73 & 0.18 & $0.00^{*}$ & 2.06 & $1.45-2.94$ \\
\hline More worry & 1.02 & 0.23 & $0.00^{*}$ & 2.78 & $1.78-4.33$ \\
\hline Very worry & 1.28 & 0.26 & $0.00^{*}$ & 3.58 & $2.15-5.95$ \\
\hline Constant & 0.82 & 0.21 & $0.00^{*}$ & - & - \\
\hline
\end{tabular}

$\mathrm{Cl}=$ Confidence Intervals, $\mathrm{OR}=$ Odds Ratio.

${ }^{*} \mathrm{P}<0.05$.

that men were less likely to adopt comprehensive precautionary measures against $\mathrm{H} 7 \mathrm{~N} 9$, such as washing hands and reducing social events. A deeper understanding of the root causes of such differential risk behavior can help inform the development of dissemination strategies directed at different subgroups. Several previous studies have also indicated that men are less likely to follow behavioral recommendations (such as hand washing) to prevent the transmission of H1N1 influenza, SARS, and other infectious diseases [17-19]. Therefore, men need special targeting for health education, especially to improve their knowledge of influenza, because knowledge of influenza and perceived effectiveness of personal hygiene practices (PHPs) has been shown to be associated with PHPs [20].

We found that more than one-third of participants stated that after the emergence of H7N9, they no longer bought chickens or other poultry to eat. A previous study has revealed that perceived theoretical threat from poultry was associated with less buying of live poultry [21]. We should be aware that the prolonged warning that a future pandemic could be sparked by avian influenza viruses is likely to cause pandemic fatigue in the public, and would probably not change their perception of avian influenza risk and associated protective behavior [22]. Some causal 
beliefs and lay perceptions of avian influenza contradicted public health efforts at control [23]. Therefore, more effort should be made to improve compliance of proper preventive measures and reduce panic among the public. In addition, because the Guangzhou population faces risks from the high prevalence of exposure during purchase and poultry rearing [24], better management for raising and selling poultry in Guangzhou is needed.

The high proportion $(84.00 \%)$ of participants indicating a willingness to receive H7N9 vaccine if it is available bodes well for influenza prevention through vaccination in Guangzhou. Of those whose response was "no", the primary reason for unwillingness to accept a vaccine was concern about the safety of the new vaccine. A similar finding was also observed during the $\mathrm{pH} 1 \mathrm{~N} 1$ pandemic in Hong Kong, which indicated that perceived risk from the pH1N1 vaccine could inhibit $\mathrm{pH} 1 \mathrm{~N} 1$ vaccine uptake [25]. These results suggest that some participants lacked an understanding of the process of developing influenza vaccine based on the probability of strains. While we only studied a small subset of the population in Guangzhou, if these results were found to be representative, educational materials distributed about the novel influenza vaccine should focus on its safety record, manufacturing, and the similarities between seasonal influenza vaccination and the H7N9 vaccine. These efforts could help to dispel these fears, considering that we found that participants who had received influenza vaccine within recent three years were nearly two times more likely to accept H7N9 vaccine compared with those who had not.

Although the interviewees responded a relative high willingness to receive $\mathrm{H} 7 \mathrm{~N} 9$ vaccine, in the past three years, only $33.17 \%$ actually received the seasonal influenza vaccine. This implied that the current high willingness of accepting vaccine may be attributed to the high case fatality rate of H7N9 reported, and a high proportion of participants fearing they will be infected. As indicated in this study, worry was found to be the strongest predictor of vaccination uptake. Consistent with our finding, Liao et al. also reported that perceived low risk from $\mathrm{pH} 1 \mathrm{~N} 1$ could inhibit pH1N1 vaccine uptake [21]. That means if the public believes that the severity of A/H7N9 is lower, the acceptance rate may decline. During the early stage of the pH1N1 pandemic (May-June, 2009), international studies assessing willingness to receive the $\mathrm{pH} 1 \mathrm{~N} 1$ vaccine indicated rates that ranged from $36.9 \%$ [26] to $49.6 \%$ [27]. However, national data from Australia collected in November and December 2009, when the public believed that the pandemic was coming to an end [8], showed that there had only been a $14 \%$ uptake of the vaccine [28]. Therefore, combining our finding with previous published literatures suggests that when levels of worry are generally low, acting to increase the volume of mass media and advertising coverage is likely to increase the perceived efficacy of recommended behaviors, which, in turn, is likely to increase their vaccination uptake.

We showed that in response to "once H7N9 outbreaks in Guangzhou", participants' main concerns included "how to protect my family from infection?", "what is the current epidemic situation?", "is the vaccination available? Is it safe?", "is there any effective drug treatment?", and "how to conduct home disinfection?". This is similar to Aihua et al., who reported that during the 2009 H1N1 influenza pandemic, the public's primary concern was effective and easy-to-operate preventive measures [29]. Therefore, these information needs should be taken into account in future health education campaigns.

Some limitations of this study must be acknowledged. First, our subjects were employees of food production and operation, and we recognize the limitations of applying the results of this study to the general population. Second, this survey measured the participants' views at a specific point in time; therefore, the attitudes and practices reflected the information available at that time. Third, some of the questions in our questionnaire had Likert-type response options, which restricted the preferences of participants to a few options. A fourth limitation is inherent to the study design: the use of convenience sampling - as opposed to random sampling - imposes some inherent selection bias and diminishes the internal validity.

\section{Conclusions}

Taken together, despite these limitations, our study provides valuable insight into attitudes and practices related to H7N9 influenza among employees of food production and operation just three months after the first human infection case reported in China, and one month after chickens were found to be infected in Guangzhou. We found that: 1) The majority of participants worried about being infected with the A/H7N9 and took initiative to find information about H7N9. The internet, television, and newspapers were the main methods of obtaining information, and the methods differed by sex, age, and some other demographic variables. 2) Quite a number (20.28\%)of participants complained that the information was not timely enough, and $20.76 \%$ believed information was intentionally concealed by the government. Nearly one-third of participants did not firmly believe that the government could control the H7N9 epidemic. These results reflect some distrust in the health department. 3) Most participants took positive measures to prevent infection; however, more than one-third reported no longer buying chickens and other poultry to eat. A majority of participants indicated a willingness to receive an $\mathrm{A} / \mathrm{H} 7 \mathrm{~N} 9$ vaccine, and the primary reason for unwillingness to receive a vaccine was concern about safety. A history of influenza vaccination and worry about being infected with the A/H7N9 were significantly 
associated with the intention to receive an $\mathrm{H} 7 \mathrm{~N} 9$ vaccine. This suggests that more effort should be made to improve compliance of proper preventive measures and reduce panic among the public. In addition, we also reported the public's main information needs if a human H7N9 outbreak occurs in Guangzhou. These findings should be used to improve health education and develop a correct strategy for H7N9 control and prevention.

\section{Consent}

Written informed consent was obtained from the patient for the publication of this report.

\section{Additional file}

Additional file 1: Questionnaire on investigation of attitudes, practices and information needs regarding novel influenza A (H7N9).

\section{Abbreviations}

SARS: Severe acute respiratory syndrome; UK: United Kingdom; CDC: U.S. center for disease control and prevention; TV: Television; pH1N1: Pandemic (H1N1) 2009.

\section{Competing interests}

The authors declare that they have no competing interests.

\section{Authors' contributions}

All authors contributed to the design and execution of the study and analyses. TGL contributed to the conception of study and interpretation and writing of the manuscript. JF participated in the conception of the study and drafting of the manuscript. PZQ participated in the design and data collection. WSL participated in the design and statistical analysis. MXL participated in the design and data collection. XMF contributed to the manuscript writing. MW contributed to the study design, interpretation, and manuscript writing. All authors read and approved the final manuscript.

\section{Acknowledgements}

This work was supported by the Research Fund from the Health Bureau of Guangzhou (grant number 201102A212006), Science and Technology Bureau of Guangzhou (grant number 2012Y2-00020) and Guangdong Science and Technology Program (grant number 2012B040304002). All enrollees who participated in the study are appreciated. We wish to give special thanks to Dr. Doug Thoroughman, Dr. John Poe, Dr. Sara Robeson, and Dr. Kraig Humbaugh from the Kentucky Department for Public Health (USA) for their epidemiology guide.

\section{Author details}

'Guangzhou Center for Disease Control and Prevention, No 1, Qide Rd, Jiahe, Baiyun District, Guangzhou, Guangdong Province 510440, China. 'Basic Medical College, Inner Mongolia Medical University, Hohhot 010059, China.

Received: 11 July 2013 Accepted: 24 December 2013

Published: 2 January 2014

\section{References}

1. Gao R, Cao B, Hu Y, Feng Z, Wang D, Hu W, Chen J, Jie Z, Qiu H, Xu K, et al: Human infection with a novel avian-origin influenza $A(H 7 N 9)$ virus. N Engl J Med 2013, 368:1888-1897.

2. Ke Y, Wang Y, Zhang W, Huang L, Chen Z: Deaths Associated with Avian Influenza A(H7N9) Virus in China. Ann Intern Med 2013, 159:159-160.

3. National health and family planning commission of the people's republic of China: overview of people infected with avian influenza A (H7N9) in China [in Chinese]. http://www.nhfpc.gov.cn/yjb/s3578/201307/75a172fb9cf54ede8f9 6da5c3f72efd4.shtml.
4. Mei Z, Lu S, Wu X, Shao L, Hui Y, Wang J, Li T, Zhang H, Wang X, Yang F, et al: Avian Influenza A(H7N9) Virus Infections, Shanghai, China. Emerg Infect Dis 2013, 19:1179-1181.

5. Chen Y, Liang W, Yang S, Wu N, Gao H, Sheng J, Yao H, Wo J, Fang Q, Cui D, et al: Human infections with the emerging avian influenza A H7N9 virus from wet market poultry: clinical analysis and characterisation of viral genome. Lancet 2013, 381:1916-1925.

6. Pavia AT: Influenza A (H7N9): From Anxiety to Preparedness. Ann Intern Med 2013, 159:219-220.

7. Li T, Fu C, Di B, Wu J, Yang Z, Wang Y, Li M, Lu J, Chen Y, Lu E, et al: A two-year surveillance of 2009 pandemic influenza A (H1N1) in Guangzhou, China: from pandemic to seasonal influenza? PLoS One 2011, 6:e28027.

8. Seale H, Heywood AE, McLaws M-L, Ward KF, Lowbridge CP, Van D, Maclntyre CR: Why do I need it? I am not at risk! Public perceptions towards the pandemic (H1N1) 2009 vaccine. BMC Infect Dis 2010, 10:99.

9. Seale H, McLaws M, Heywood A, Ward K, Lowbridge C, Van D, Gralton J, Maclntyre C: The community's attitude towards swine flu and pandemic influenza. MJA 2009, 191:267-269.

10. Goodwin R, Haque S, Neto F, Myers LB, Goodwin R, Haque S, Neto F, Myers LB: Initial psychological responses to Influenza A, H1N1 ("Swine flu"). BMC Infect Dis 2009, 9:166.

11. Jones $J \mathrm{H}$, Salathe M: Early assessment of anxiety and behavioral response to novel swine-origin influenza A(H1N1). PLOS ONE 2009, 4:e8032.

12. Rubin G, Amlot R, Page L, Wessely S: Public perceptions, anxiety, and behaviour change in relation to the swine flu outbreak: cross sectional telephone survey. BMJ 2009, 339:b2651.

13. Balkhy HH, Abolfotouh MA, Al-Hathlool RH, Al-Jumah MA: Awareness, attitudes, and practices related to the swine influenza pandemic among the Saudi public. BMC Infect Dis 2010, 10:42

14. Elledge BL, Brand M, Regens JL, Boatright DT: Implications of public understanding of avian influenza for fostering effective risk communication. Health Promot Pract 2008, 9(4 Suppl):54S-9S

15. Finkelstein J, Bedra M: Is Internet Search Better than Structured Instruction for Web-Based Health Education? Stud Health Technol Inform 2013, 190:65-67.

16. Lau JT, Griffiths S, Choi KC, Tsui HY: Widespread public misconception in the early phase of the H1N1 influenza pandemic. J Infect 2009, 59:122-127.

17. Lau JTF, Yang $X$, Tsui $H$, Kim JH: Monitoring community responses to the SARS pandemic in Hong Kong: from day 10 to day 62. J Epidemiol Community Health 2003, 57:864-870.

18. Tang CSK, Wong C-Y: Factors influencing the wearing of facemasks to prevent the severe acute respiratory syndrome among Chinese in Hong Kong. Prev Med 2004, 39:1193.

19. Leung GM, Ho LM, Chan SK, Ho SY, Bacon-Shone J, Choy RY, Hedley AJ, Lam TH, Fielding R: Longitudinal assessment of community psychobehavioral responses during and after the 2003 outbreak of severe acute respiratory syndrome in Hong Kong. Clin Infect Dis 2005, 40:1713-20.

20. Liao Q, Cowling BJ, Lam WW, Fielding R: The influence of social-cognitive factors on personal hygiene practices to protect againstinfluenzas: using modelling to compare avian $\mathrm{A} / \mathrm{H} 5 \mathrm{~N} 1$ and 2009 pandemic $\mathrm{A} / \mathrm{H} 1 \mathrm{~N} 1$ influenzas inHong Kong. Int J Behav Med 2011, 18:93-104.

21. Liao Q, Lam WW, Jiang CQ, Ho EY, Liu YM, Zhang WS, Richard F: Avian influenza risk perception and live poultry purchase in Guangzhou, China, 2006. Risk Anal 2009, 29:416-424.

22. Liao Q, Cowling BJ, Lam WT, Fielding R: Changing perception of avian influenza risk, Hong Kong, 2006-2010. Emerg Infect Dis 2011, 17:2379-2380.

23. Liao QY, Lam WW, Dang VT, Jiang CQ, Udomprasertgul V, Fielding R: What causes H5N1 avian influenza? Lay perceptions of H5N1 a etiology in South East and East Asia. J Public Health 2009, 31:573-581.

24. Liao Q, Lam WT, Leung GM, Jiang C, Fielding R: Live poultry exposure, Guangzhou, China, 2006. Epidemics 2009, 1:207-212.

25. Liao Q, Cowling BJ, Lam WW, Fielding R: Factors affecting intention to receive and self-reported receipt of 2009 pandemic (H1N1) vaccine in Hong Kong: a longitudinal study. PLoS One 2011, 6:e17713.

26. Sypsa V, Livanios T, Psichogiou M, Malliori M: Public perceptions in relation to intention to receive pandemic influenza vaccination in a random population sample: evidence from a cross-sectional telephone survey. European Communicable Disease Bulletin 2009, 14:19437.

27. Maurer J, Harris KM, Parker A, Lurie N, Maurer J, Harris KM, Parker A, Lurie N: Does receipt of seasonal influenza vaccine predict intention to receive 
novel H1N1 vaccine: evidence from a nationally representative survey of U.S. adults. Vaccine 2009, 27:5732-5734.

28. Australian Institute of Health and Welfare: 2009 Adult Vaccination Survey Provisional topline results for H1N1 vaccination uptake. Canberra: Australian Government Department of Health and Ageing; 2010.

29. Aihua H, Yansha C, Wenru F, Ming W: Investigation on information needs towards influenza pandemic among public in Guangzhou [Article in Chinese]. Chinese Journal of Epidemiology 2009, 11:1117-1120

doi:10.1186/1471-2334-14-4

Cite this article as: Li et al:: Attitudes, practices and information needs regarding novel influenza $A$ (H7N9) among employees of food production and operation in Guangzhou, Southern China: a cross-sectional study. BMC Infectious Diseases 2014 14:4.

\section{Submit your next manuscript to BioMed Central and take full advantage of:}

- Convenient online submission

- Thorough peer review

- No space constraints or color figure charges

- Immediate publication on acceptance

- Inclusion in PubMed, CAS, Scopus and Google Scholar

- Research which is freely available for redistribution 